\title{
Adverse Childhood Experiences and Rate of Memory Decline From Mid to Later- Life: Evidence From the English Longitudinal Study of Ageing
}

Brendan Q. O'Shea, Panayotes Demakakos, Dorina Cadar, and Lindsay C. Kobayashi

Editorial correspondence should be directed to Mr. Brendan O'Shea, Department of

Epidemiology, University of Michigan School of Public Health, 1415 Washington

Heights, SPH I Ann Arbor, MI, United States, 48103 (e-mail: broshea@umich.edu), Tel:

+1 (248) 403-9051, Fax: 734-763-5706

Author affiliations: Department of Epidemiology, University of Michigan School of Public Health, Ann Arbor, MI, United States (Brendan Q. O'Shea and Lindsay C. Kobayashi);

Department of Epidemiology and Public Health, University College London, London, United Kingdom (Panayotes Demakakos); and Department of Behavioural Science and Health, University College London, London, United Kingdom (Dorina Cadar)

(C) The Author(s) 2021. Published by Oxford University Press on behalf of the Johns Hopkins Bloomberg School of Public Health. All rights reserved. For permissions, please e-mail:

journals.permissions@oup.com. 
Funding: None to report.

Conflict of interest: All authors have no conflicts of interest to declare.

Running head: Adverse Childhood Experiences and Memory

\section{ABSTRACT}

Evidence on the role of early-life adversity in later-life memory decline is conflicting. We investigated the relationships between adverse childhood experiences (ACEs) and memory performance and rate of decline over a ten-year follow-up among mid-to-older adults in England. Data were from biennial interviews with 5,223 participants aged 54+ in the population-representative English Longitudinal Study of Ageing from 2006/072016/17. We examined self-reports of nine ACEs prior to age 16, which related to abuse, household dysfunction, and separation from family. Memory was assessed at each time point as immediate and delayed recall of 10 words. Using linear mixed-effects models with person-specific random intercepts and slopes and adjusted for baseline age, age ${ }^{2}$, sex, ethnicity, and childhood socioeconomic factors, we observed that most individual and cumulative ACE exposures had null-to-weakly negative associations with memory function and rate of decline over the 10-year follow-up. Having lived in residential or foster care was associated with lower baseline memory (adjusted $\beta=$ -

0.124 standard deviation units, $95 \%$ confidence interval: $-0.273,-0.025)$, but not memory decline. Our findings suggest potential long-run impacts of residential or foster 
care on memory, and highlight the need for accurate and detailed exposure measures when studying ACEs in relation to later-life cognitive outcomes.

Keywords: aging, adverse childhood experiences; longitudinal cohort study; cognitive aging

Abbreviations: ACEs, adverse childhood experiences; ELSA, English Longitudinal Study of Ageing; $\mathrm{Cl}$, confidence interval

The number of people living with dementia worldwide is expected to reach 152 million by 2050 , and the estimated global cost of dementia is expected to reach $\$ 2$ trillion US dollars by 2030 (1). Dementia results in a myriad of symptoms that have a detrimental impact on quality of life, and progressively disables individuals from living with optimal functioning without assistance (2). The causes of dementia remain poorly understood, and epidemiological evidence indicates that dementia etiology could have its origins in early-life $(3,4)$. Episodic memory loss is a hallmark of dementia and one of its earliest symptoms, indicative of a long dementia prodrome (5-7). Little is known about the role of adverse childhood experiences (ACEs) in shaping the rate of long-term memory decline in later-life (8).

ACEs are characterized as adverse or traumatic events that occur during childhood (9-14) and have been associated with health risks across the life course. A systematic review of 37 observational studies found consistent associations between experiencing a variety of ACEs and adverse health behaviors in adulthood, such as physical inactivity, smoking, drug use, and alcohol use, as well as chronic disease outcomes including heart disease, respiratory disease, and cancer $(9,15-17)$. We identified only three existing longitudinal studies on ACEs and cognitive aging 
outcomes, with conflicting results. The Chicago Health and Aging Project observed protective associations between not having enough food or being thin in childhood and rate of cognitive decline over 16-years in Black and African Americans, but not White Americans (18). The 1958 British Birth Cohort Study observed negative associations between abuse reported in childhood and subsequent domain-specific cognitive functions in adolescence and at age 50 (19). The Longitudinal Aging Study Amsterdam observed that ACEs were associated with rate of change in processing speed, but not memory, over 10 years, but this association was restricted to older adults who were depressed (20). Other studies are cross-sectional, some limited by small sample size, and findings are of conflicting directions and magnitudes (21-25).

The lack of consistency observed in the few longitudinal studies conducted to date is somewhat surprising, given the plausibility of direct neurobiological (26-28) and indirect social and behavioral pathways $(10,12,29-34)$ between ACEs and later-life cognitive health outcomes according to life course epidemiological frameworks (35). To help resolve some of these inconsistencies and build the longitudinal evidence base on this topic, we aimed to investigate individual and cumulative relationships between nine self-reported ACEs prior to age 16, and subsequent memory function and decline over a 10-year follow-up among adults aged 54 and over in the population-representative English Longitudinal Study of Ageing. We hypothesized that older adults who reported any previous ACEs would have lower baseline memory and faster rates of aging-related memory decline. We also hypothesized that there would be a dose-response relationship between the cumulative number of reported ACEs and baseline memory 
function and decline over the follow-up, consistent with evidence for other chronic disease outcomes $(9,15,16)$.

METHODS

English Longitudinal Study of Ageing

The English Longitudinal Study of Ageing (ELSA) is a nationally representative cohort study of men and women ages $\geq 50$ living in private households that began with Wave 1 in 2002/03 (N=12,099) (36). The ELSA study design and methodology have been well-documented elsewhere (36). Participants are followed up in biennial data collection waves consisting of in-person interviews and self-completion questionnaires (36). In 2007, after ELSA Wave 3, a Life History interview took place. The Life History Interview consisted of a computer-aided personat interview and a self-completion questionnaire that collected data on early and mid-life events including ACEs (37). The present study used Wave 3 core interview and Life History data (collected in 2006/07) as the baseline, when participants were aged $\geq 54$ years, with follow-up for memory outcomes every two years, through to ELSA Wave 8 (2016/17).

Study sample

Eligible participants were ELSA core sample members who completed the Wave 3 core and Life History interviews and self-completion questionnaires, who were free of Alzheimer's disease and dementia with non-proxy interviews at Wave 3 with complete covariate data, and, who had completed the ELSA cognitive assessment at any point over the follow-up (2006/07-2016/17), for a total analytical sample of 5,223 (Figure 1). Outcome: memory 
During the in-person ELSA core interviews, participants completed a series of cognitive assessments with trained interviewers (38). Memory was assessed as immediate and delayed recall of a 10-word list (one point per word recalled, for a total of 20 points) at each ELSA time point from Wave $3(2006 / 07)$ to Wave $8(2016 / 17)(38)$. We z-standardized the composite 20-point scores at Wave 3, such that they had a mean of 0 and standard deviation of 1 . Scores at each follow-up wave were standardized to the Wave 3 distribution, to allow us to assess change relative to the study baseline distribution (39). Changes in memory function over the follow-up are thus interpreted as changes in standard deviation units of the Wave 3 (baseline) distribution over two-year intervals.

Exposure: adverse childhood experiences

The current literature lacks a standard definition of ACEs $(9-12,14,40,41)$. The landmark Kaiser ACE study focused on ACEs in the domains of child abuse (physical, psychological, and sexual abuse) and household dysfunction (substance use, mental illness, criminal behavior, violence) $(9,13,41)$. The Kaiser ACE study has been used as a guide by many later studies, and, indeed, a content analysis of the ACE literature identified child abuse as the most commonly studied ACE in relation to subsequent health outcomes (40). We used the Kaiser ACE Study framework to construct our ACE measures, consistent with previous research using the ELSA data $(42,43)$. We thus focus on ACEs related to abuse, household dysfunction, and separation from family in childhood. These ACEs are considered as distinct exposures from family socioeconomic conditions in childhood, although family socioeconomic indicators may be important confounders of the ACE-memory aging relationships. 
We derived measures of ACEs from the Wave 3 ELSA core interview and Life History interview and self-completion questionnaire. We constructed nine distinct ACE measures that are related to abuse, household dysfunction, and separation from family (all yes/no for the first instance of the ACE happening before age 16): physically abused by parents; experienced a serious physical attack or assault; was a victim of sexual assault (including rape or harassment); parents drank excessively, took drugs, or had mental health problems; parents argued or fought often; ever separated from mother for $\geq 6$ months (not due to death of mother); death of mother; spent most of childhood in a single-mother family; been in residential care institution or foster family. We also included a dichotomous indicator for having experienced any ACE versus no ACEs, and a cumulative ACE exposure variable (ranging from 0 to 3 + total ACEs), to assess doseresponse relationships with memory outcomes (42).

Covariates

Any confounders of the associations between ACEs and later-life memory would have to arise in early-life. We thus considered sex (male, female), baseline age (continuous), baseline age ${ }^{2}$ (continuous), and ethnicity (white, non-white) as timeinvariant potential early-life confounders. We also considered measures of family socioeconomic conditions in childhood as potential confounders of the ACE-memory relationships: self-reported experience of financial hardship during childhood (yes, no), self-reported father's occupation when the respondent was 14 (categorical, consisting of 4 skill level classes derived from the International Standard Classification of Occupations) (44), number of books in the household when the respondent was 10 ranging from 0 to $200+$ (ordinal, coded $0-4$ ), and total household amenities during 
childhood (continuous, ranging 0-5 for identifying each of the following: fixed bath, cold running water, hot running water, inside toilet, central heating) (43). The mean VIF for these four variables was 1.00 , indicating no multicollinearity. The timing of these reported childhood socioeconomic factors is not well-defined with respect to our ACE measures, which were events that occurred for the first time before age 16. Thus, while our primary interest in these variables is in their roles as potential confounders, they could possibly mediate any observed associations or, if caused by a given ACE as well as any unmeasured factors that also affect later-life memory, could potentially be colliders of the ACE-memory relationships.

Statistical analyses

We described characteristics of the sample overall and according to reported ACE exposures. We used multivariable-adjusted linear mixed-effects models with random person-specific intercepts and slopes to assess the relationships between ACEs and baseline memory function (Wave 3; 2006/07) and rate of memory decline (Waves 3 through 8; 2006/07 to 2016/17). To account for potential selection bias due to non-response to the Life History interview at Wave 3, we applied person-level nonresponse weights to all models (37). We ran two sets of models: Model Set 1 adjusted for baseline age, baseline age ${ }^{2}$, sex, and ethnicity, and Model Set 2 additionally adjusted for the four childhood socioeconomic exposures. For each model set, ACEs were modelled individually, and then in summation to investigate dose-response relationships with the memory outcomes. We tested interactions between all covariates and time, none of which were included as they were not statistically significant. We tested for and observed no interactions between ACEs and sex in predicting memory 
function and decline, therefore all analyses were conducted with both sexes combined. Finally, as the rate of memory aging is known to accelerate with increasing age, we tested for quadratic and cubic memory decline slopes, using likelihood ratio tests with maximum likelihood estimation to assess model fit (45). The final, weighted models were estimated using maximum likelihood with an unstructured correlation matrix for the random effects, allowing the correlations between the intercepts and slopes to be estimated.

Sensitivity analyses. To assess potential differential recall of ACEs based on prior memory function, we assessed whether memory score at Wave 1 of ELSA (2002/03) predicted recollection of any ACE at Wave 3 (2006/07) using a logistic regression model adjusted for age, sex, and ethnicity. We assessed the potential for attrition bias by comparing study attrition according to ACE exposure status, and ran joint models with a shared random effect linking a longitudinal sub-model for repeated episodic memory measures and a flexible parametric survival sub-model for study attrition (46). Detailed methods are shown in Web Appendix. All analyses were performed using Stata/SE 16.0 (College Station, TX).

\section{RESULTS}

Mean (standard deviation) age at baseline (2006/07) was 68 (9) years, just over half the sample was female $(2,906 / 5,223)$, and $1 \%$ were non-white $(74 / 5,223$; Table 1$)$. Overall, $38 \%(1,985 / 5,223)$ of participants reported experiencing at least one ACE (Table 1). The most commonly reported ACE was having parents who argued or fought very often $(18 \% ; 933 / 5,223)$, and the least commonly reported ACE was experiencing a serious physical attack or assault (1\%; 56/5,223; Web Table 1$)$. The median follow-up time of 
the analytical sample was 4.9 years (IQR $=3.5$ to 5.0 years). Mean memory function declined over time, relative to the baseline, among those who remained in the study and individuals with no ACEs made up a slightly smaller share of the sample over time (Web Table 1).

Table 2 presents linear estimates and associated 95\% confidence intervals (CI) for the associations between ACEs and memory function at baseline (2006/07) and change over time (2006/07 to 2016/17), with non-linear estimates visualized in Figure 2, to aid in their interpretation. Having lived in a residential care institution or foster care was associated with lower mean baseline memory score in Modél Set 1 ( $\beta=-0.190$; 95\% Cl: $-0.343,-0.036$; Table 2). This association was attenuated somewhat when the childhood socioeconomic variables were included in the model $(\beta=-0.124 ; 95 \% \mathrm{Cl}$ : 0.273, 0.025; Table 2). Point estimates for other ACEs, including having experienced any ACE, were generally close to the null (Table 2). Non-linear memory aging slopes were of better fit for all ACEs than linear slopes, although the associations were similar in both specifications and the differences in rates of memory decline between individuals with and without ACEs were negligible (Table 2; Figure 2). We observed an imprecise dose-response relationship between cumulative number of ACEs and baseline memory function, and no relationship with rate of memory decline (Table 3; Figure 3).

Recollection of ACEs in Wave 3 (baseline of this analysis) did not vary by prior memory function at Wave $1(\mathrm{OR}=1.00 ; 95 \% \mathrm{Cl}: 0.93,1.08$, for any vs. no ACEs, per standard deviation increase in memory function). Results from the unweighted joint models for longitudinal memory change and study attrition, shown in Web Table 2, were 
consistent with those shown in Table 2, as well as with unweighted linear mixed-effects models shown in Web Table 3, indicating that bias due to differential attrition is negligible in in this analysis.

\section{DISCUSSION}

Capturing ten years of follow-up data from a nationally representative cohort of English adults aged 54 and over, we generally observed null associations between nine ACEs and later-life memory function and decline. Having been in a residential care institution or fostered prior to the age of 16 was predictive of poorer memory at baseline, but not with change over time. This association was eight times stronger in magnitude than a one-year increase in age on baseline memory function in the fully-adjusted model. Inclusion of childhood socioeconomic circumstances attenuated this association by just over one-third, indicating that these factors have some overlap, but that living in residential or foster care as a child may have a unique role in memory aging that deserves further investigation.

Comparison with other literature

Our findings of mostly null associations between ACEs and memory outcomes are inconsistent with several cross-sectional studies that identified negative associations between various ACEs and cognitive health in mid-to-later life (19, 22-25, 47). Evidence from the few longitudinal studies on this topic is conflicting, and uses inconsistent measures of ACEs and cognitive outcomes. For example, the Longitudinal Aging Study Amsterdam defined ACEs as "any significant life events before the age of 18 years which had a lasting impact on the rest of their life" (20, p.130). The Chicago 
Health and Aging Project expanded their definition of ACEs to include nutritional factors, and observed unexpected protective associations between going without food and being thin as a child with the rate of memory decline in older Black and African Americans, but not in older White Americans (18). The Kuopio Ischemic Heart Disease Risk Factor Study of Finnish men found that living in custody and experiencing a crisis or migration due to war were associated with an increased incidence of Alzheimer's disease and dementia over a 22-year follow-up (21). A longitudinal study of 17,412 older adults Japan who grew up during World War 2 found that reporting three or more ACEs related to abuse, family psychopathology, or family lóss was associated with increased dementia risk over a three-year follow-up from 2013-2016 (8). While certain ACEs may be period- or population-specific (e.g.experiences of violence due to war), these inconsistencies highlight a need for a consistently applied definition and operationalization of ACE measures in order to support inference across the body of literature.

While the predominant Kaiser ACE framework excludes socioeconomic factors as ACEs, it is important to recognize that broader socioeconomic conditions may structure the risk of experiencing ACEs such as household dysfunction, and family separation. There is a large and consistent body of literature linking childhood socioeconomic factors to cognitive function, decline, and dementia risk in later-life (4851). Some ACE studies have considered socioeconomic exposures in their ACE framework, such as the Chicago Health and Aging Project, which found that being very poor was associated with more rapid cognitive decline (18). We recommend for future studies to carefully delineate specific ACEs from socioeconomic factors, and adjust for 
early-life socioeconomic factors as confounders, where appropriate. The use of ACE measures consistent with the original Kaiser ACE study may provide the greatest consistency with previous literature, in addition to standardized cognitive outcomes. However, we note there are many early-life experiential factors aside from ACEs, such as illness and nutrition, that are of substantive interest with respect to associations with adult health and should be investigated, but potentially outside of the ACEs framework. Potential mechanisms

We hypothesized that ACEs would have negative relationships with later-life memory outcomes, which we postulated to be through direct neurobiological impacts of early life stressors as well as indirect pathways through social factors known to influence later-life memory, such as educationalattainment, employment, and social networks $(10,12,26-28,33-35)$. However, either most of the ACEs assessed in this study truly have no association with memory in later-life, or another causal or artefactual mechanism is responsible for these unexpected null associations. They may also not have an impact on this population, where childhood financial hardship was rare $(<5 \%$ of the sample) and $70 \%$ of the sample had secondary or post-secondary education.

Cognitive reserve is one potential causal explanation that requires further inquiry (52-54). It may be that individuals in our study who reported ACEs had obtained reserve throughout their lifetimes and were able to maintain healthy cognitive aging despite potentially having experienced neurological impacts of early-life adversity. Educational attainment, a key contributor to cognitive reserve, was similar between those who did and did not experience ACEs, which was somewhat unexpected given the "chains of risk" influences that ACEs are thought to have throughout the life course 
$(10,12,29-34)$. Similar to reserve, resilience is a process through which individuals can positively adapt in response to adversity $(55,56)$. In our study, unmeasured resilience factors may have played a role in enabling our sample to maintain memory function into later adulthood despite having experienced childhood adversity. Limitations and strengths

Our results could alternatively be explained by methodological artefact due to study limitations. A key limitation is information bias. The ELSA assessed ACEs as binary measures of whether participants had experienced a given event or not during their childhood. We were unable to quantify variation in other aspects of the ACEs, such as the specific age(s) at which the ACE occurred, the frequency, duration, severity of the ACE, or its psychological impact at the time or afterwards. These factors have been shown to contribute to variation in the impact of early-life adversity on brain development $(57,58)$. We also did not have data on all possible ACEs that could be experienced, such as paternal death. While the brevity of the ACE measures in ELSA enabled their inclusion in a large, population-based study alongside rich covariate and outcome data, more detailed, precise measures of childhood adversity may be needed to obtain accurate estimates of the relationships between childhood adversity and memory decline.

ELSA sample members who had proxy interviews with a family member were excluded from this study. However, it is unlikely that the exclusion of proxies introduced bias, as only $82 / 5,223$ sample members transitioned into having a proxy interview with proxy-reported cognitive impairment (defined as scoring $>3.38$ on the Informant Questionnaire on Cognitive Decline in the Elderly; IQCODE). Despite the use of a life 
history calendar to aid with recall, our results may have been biased by recall error in a direction that is difficult to predict. We may also have underestimated the relationships between ACEs and memory outcomes if individuals who experienced the most severe ACEs differentially died prior to the time of this study or not participated, if they had worse memory, on average, than those who did not experience ACEs. There is a chance that type I error may explain the observed association between having been in a residential care institution and baseline memory function, given that we estimated 18 associations for the ACEs in Table 2. This association requires investigation in other studies for confirmation.

Strengths of this study include the large, population-representative nature of the ELSA, with 10 years of follow-up data using reliable measures of episodic memory (59). These features allowed us to conduct one of the first longitudinal studies on the relationships between individual and eumulative ACEs and the rate of memory aging over an entire decade in an older study sample. By applying non-response weights to our analysis, we were able, to account for differential response to the Life History interview that captured our exposure measures. Our use of linear mixed-effects models allowed us to retain all available outcome data on individuals in estimating the memory intercepts and slopes, even if they dropped out of the study. We do not expect our findings to be affected by learning effects in cognitive testing, as the Wave 3 interview was the third cognitive assessment for the study sample.

\section{Conclusion}

In this longitudinal study of adults aged 54 years and older in England, we observed that individual and cumulative ACEs had null-to-weakly negative associations 
with memory function and decline over a 10-year period during aging. We found that having lived in residential or foster care as a child was associated with lower baseline memory with a magnitude equivalent to approximately eight years of increased age. Overall, this study illustrates the potentially complex nature of early-life predictors of memory aging and suggests that the neurobiological and social impacts of most standard ACEs may not strongly apply to memory aging in the older English population. Future studies should obtain comprehensive and consistent measures of childhood adversity and triangulate relationships observed across different populations and study designs.

\section{Acknowledgements}

The English Longitudinal Study of Ageing was developed by a team of researchers based at the University College London, NatCen Social Research, and the Institute for Fiscal Studies. The data were collected by NatCen Social Research. The funding is currently provided by the National Institute of Aging (R01AG017644), and a consortium of UK government departments coordinated by the National Institute for Health Research. 


\section{REFERENCES}

1. Alzheimer's Disease International. World Alzheimer Report 2019: Attitudes to dementia, 2019. London, UK.

https://www.alzint.org/u/WorldAlzheimerReport2019.pdf. Published September 2020. Accessed May 5, 2020.

2. National Institute on Aging, US Department of Health and Human Services. What is Dementia? Symptoms, Types, and Diagnosis. https://www.nia.nih.gov/health/whatdementia-symptoms-types-and-diagnosis. Updated Dec 31, 2017. Accessed May $5,2020$.

3. Dekhtyar S, Wang H-X, Scott K, et al. A Life-Course Study of Cognitive Reserve in Dementia-From Childhood to Old Age. American Journal of Geriatric Psychiatry. 2015;23(9):885-96.

4. Marden JR, Tchetgen EJ, Kawachi I, et al. Contribution of Socioeconomic Status at 3 Life-Course Periods to Late-Life Memory Function and Decline: Early and Late Predictors of Dementia Risk. American Journal of Epidemiology. 2017;186(7):80514.

5. Bowen J,Teri L, Kukull W, et al. Progression to dementia in patients with isolated memory loss. The Lancet. 1997;349(9054):763-5.

6. Wilson RS, Leurgans SE, Boyle PA, et al. Cognitive Decline in Prodromal Alzheimer Disease and Mild Cognitive Impairment. Archives of neurology (Chicago). 2011;68(3):351-356. 
7. Amieva H, Le Goff M, Millet X, et al. Prodromal Alzheimer's disease: successive emergence of the clinical symptoms. Ann Neurol. 2008 Nov;64(5):492-8.

8. Tani Y, Fujiwara T, Kondo K. Association Between Adverse Childhood Experiences and Dementia in Older Japanese Adults. JAMA Network Open. 2020 Feb 5;3(2):e1920740.

9. Felitti VJ, Anda RF, Nordenberg D, et al. Relationship of Childhood Abuse and Household Dysfunction to Many of the Leading Causes of Death in Adults: The Adverse Childhood Experiences (ACE) Study. American Journal of Preventive Medicine. 1998;14(4):245-58.

10. Iniguez KC, Stankowski RV. Adverse Childhood Experiences and Health in Adulthood in a Rural Population-Based Sample. Clinical Medicine \& Research. 2016 Dec 1;14(3-4):126-37.

11. Poole JC, Dobson KS, Pusch D. Childhood adversity and adult depression: The protective role of psychological resilience. Child Abuse \& Neglect. 2016;64:89-100.

12. Jones TM, Nurius $P$, Song $C$, et al. Modeling life course pathways from adverse childhood experiences to adult mental health. Child Abuse \& Neglect. 2018 Jun $1 ; 80: 32-40$.

13. Centers for Disease Control and Prevention. Preventing Adverse Childhood Experiences.

https://www.cdc.gov/violenceprevention/aces/fastfact.html?CDC_AA_refVal=https 
\%3A\%2F\%2Fwww.cdc.gov\%2Fviolenceprevention\%2Facestudy\%2Ffastfact.html. Updated Apr 3, 2020. Accessed May 5, 2020.

14. Kobayashi LC, Glymour MM, Kahn K, et al. Childhood deprivation and later-life cognitive function in a population-based study of older rural South Africans. Social Science \& Medicine. 2017 Oct 1;190:20-8.

15. Mersky JP, Topitzes J, Reynolds AJ. Impacts of adverse childhood experiences on health, mental health, and substance use in early adulthood: A cohort study of an urban, minority sample in the U.S. Child Abuse \& Neglect.2013;37(11):917-25.

16. Dube SR, Felitti VJ, Dong M, et al. The impact of adverse childhood experiences on health problems: evidence from four birth cohorts dating back to 1900. Preventive Medicine. 2003;37(3):268-77.

17. Hughes K, Bellis MA, Hardcastle KA, et al. The effect of multiple adverse childhood experiences on health: a systematic review and meta-analysis. The Lancet Public Health. 2017 Aug 1;2(8):e356-66.

18. Barnes LL, Wilson RS, Everson-Rose SA, et al. Effects of early-life adversity on cognitive declíne in older African Americans and whites. Neurology. 2012 Dec $11 ; 79(24): 2321-7$.

19. Geoffroy M-C, Pinto Pereira S, Li L, et al. Child Neglect and Maltreatment and Childhood-to-Adulthood Cognition and Mental Health in a Prospective Birth Cohort. Journal of the American Academy of Child \& Adolescent Psychiatry. 2016;55(1):3340.e3. 
20. Korten NCM, Penninx BWJH, Pot AM, et al. Adverse childhood and recent negative life events: Contrasting associations with cognitive decline in older persons. Journal of Geriatric Psychiatry and Neurology. 2014;27(2):128-38.

21. Donley GAR, Lönnroos E. Association of childhood stress with late-life dementia and Alzheimer's disease: The KIHD study. European journal of public health. 2018;28(6):1069-73.

22. Petkus AJ, Lenze EJ, Butters MA, et al. Childhood Trauma is Associated with Poorer Cognitive Performance in Older Adults. The Journal of clinical psychiatry. $2018 ; 79(1)$.

23. Jiménez E, Solé B, Arias B, et al. Impact of childhood trauma on cognitive profile in bipolar disorder. Bipolar Disorders. 2017 Aug 1;19(5):363-74.

24. Gould F, Clarke J, Heim C, et al. The effects of child abuse and neglect on cognitive functioning in adulthood. Journal of Psychiatric Research. 2012;46(4):500-6.

25. Ritchie K, Jaussent I, Stewart R, et al. Adverse childhood environment and late-life cognitive functioning. International Journal of Geriatric Psychiatry. 2011 May $1 ; 26(5): 503-10$.

26. Teicher MH, Andersen SL, Polcari A, et al. The neurobiological consequences of early stress and childhood maltreatment. Neuroscience and Biobehavioral Reviews. 2003;27(1):33-44. 
27. Teicher MH, Andersen SL, Polcari A, et al. Developmental neurobiology of childhood stress and trauma. Psychiatric Clinics of North America. 2002 Jan 1;25(2):397-426.

28. Devanand DP, Pradhaban G, Liu X, et al. Hippocampal and entorhinal atrophy in mild cognitive impairment: Prediction of Alzheimer disease. Neurology. 2007 Mar 13;68(11):828-36.

29. Carvalho A, Rea IM, Parimon T, et al. Physical activity and cognitive function in individuals over 60 years of age: a systematic review. CLINICAL INTERVENTIONS IN AGING. 2014;9:661-82.

30. Yaffe K, Fiocco AJ, Lindquist $\mathrm{K}$, et al. Predictors of maintaining cognitive function in older adults. Neurology. 2009 Jun 9;72(23):2029-35.

31. Lee Y, Back JH, Kim J, et al Systematic review of health behavioral risks and cognitive health in older adults. International Psychogeriatrics. 2010 Mar $1 ; 22(2): 174-87$.

32. Almuneef M. Long term consequences of child sexual abuse in Saudi Arabia: A report from nátional study [available online ahead of print March 11, 2019]. Child Ábuse \& Neglect. 2019 Mar 11, 2019; DOI: 10.1016/j.chiabu.2019.03.003

33. Liao J, Scholes S. Association of Social Support and Cognitive Aging Modified by Sex and Relationship Type: A Prospective Investigation in the English Longitudinal Study of Ageing. American Journal of Epidemiology. 2017;186(7):787-95. 
34. Ihle A, Gouveia ÉR, Gouveia BR, et al. The relation of education, occupation, and cognitive activity to cognitive status in old age: the role of physical frailty. International Psychogeriatrics. 2017 Sep 1;29(9):1469.

35. Kuh D, Ben-Shlomo Y, Lynch J, et al. Life course epidemiology. Journal of Epidemiology \& Community Health. 2003 Oct 1;57(10):778-83.

36. Steptoe A, Breeze E, Banks J, et al. Cohort Profile: The English kongitudinal Study of Ageing. International Journal of Epidemiology. 2013 Dec $1 ; 42(6): 1640-8$.

37. National Centre for Social Research. ELSA Wave Three: Life History Interview, 2009.

https://www.ifs.org.uk/elsa/user_guides/Wave_3_Life_History_User_Guide.pdf. Published May 2009. Accessed Jul 8,2020.

38. Banks J, Breeze E, Lessof C, et al. Retirement, health and relationships of the older population in England. The 2004 English Longitudinal Study Of Ageing (Wave 2). London, UK: Uníversity College London, Open Access publications from University Collége London. 2006

39. Glymour MM, Tzourio C, Dufouil C. Is Cognitive Aging Predicted by One's Own or One's Parents' Educational Level? Results From the Three-City Study. Am J Epidemiol. 2012 Apr 15;175(8):750-9.

40. Kalmakis KA, Chandler GE. Adverse childhood experiences: Towards a clear conceptual meaning. Journal of Advanced Nursing. 2014;70(7):1489-501. 
41. Kalmakis KA, Chandler GE. Health consequences of adverse childhood experiences: A systematic review. Journal of the American Association of Nurse Practitioners. 2015 Aug 1;27(8):457-65.

42. Demakakos P, Linara-Demakakou E, Mishra GD. Adverse childhood experiences are associated with increased risk of miscarriage in a national population-based cohort study in England. Hum Reprod. 2020 Jun 1;35(6):1451-60.

43. Demakakos $\mathrm{P}$, Lewer D, Jackson SE, et al. Lifetime prevalence of homelessness in housed people aged 55-79 years in England: its childhood correlates and association with mortality over 10 years of follow-up. Public Health. 2020 May;182:131-8.

44. International Labour Organization. International Standard Classification of Occupations 2008 (ISCO-08): Structure, group definitions and correspondence tables. Geneva, Switzerland: International Labour Office; 2012

45. Nilsson L-G. Memory function in normal aging. Acta Neurologica Scandinavica. 2003;107(s179):7-13.

46. Crowther MJ, Abrams KR, Lambert PC. Joint Modeling of Longitudinal and Survival Data. The Stata Journal. 2013 Mar;13(1):165-84.

47. Kobayashi L, Farrell M, Payne C, et al. Adverse childhood experiences and domain-specific cognitive function in a population-based study of older adults in rural South Africa. Psychol Aging. 2020; 35(6): 818-830. 
48. Cermakova P, Formanek T, Kagstrom A, et al. Socioeconomic position in childhood and cognitive aging in Europe. Neurology. 2018 Oct 23;91(17):e160210.

49. Aartsen MJ, Cheval B, Sieber S, et al. Advantaged socioeconomic conditions in childhood are associated with higher cognitive functioning but stronger cognitive decline in older age. Proc Natl Acad Sci U S A. 2019 Mar 19;116(12):5478-86.

50. Maharani A. Childhood Socioeconomic Status and Cognitive Function Later in Life: Evidence From a National Survey in Indonesia. J Geriatr Psychiatry Neurol. 2020 Jul 1;33(4):214-22.

51. Hurst L, Stafford M, Cooper R, et al. Lifetime Socioeconomic Inequalities in Physical and Cognitive Aging. Am J Public Health. 2013 Sep;103(9):1641-8.

52. Richards M, Deary IJ. A life course approach to cognitive reserve: A model for cognitive aging and development? Annals of Neurology. 2005 Oct 1;58(4):617-22.

53. Stern Y, Gurland B, Tatemichi TK, et al. Influence of Education and Occupation on the Incidence of Alzheimer's Disease. JAMA. 1994 Apr 6;271(13):1004-10.

54. Scarmeas N, Levy G, Tang M-X, et al. Influence of leisure activity on the incidence of Alzheimer's disease. Neurology. 2001 Dec 26;57(12):2236-42.

55. Connor KM, Davidson JRT. Development of a new resilience scale: The ConnorDavidson Resilience scale (CD-RISC). DEPRESSION AND ANXIETY. 2003;18(2):76-82. 
56. Werner EE. Vulnerable but invincible: high-risk children from birth to adulthood. Acta Paediatrica. 1997 Jul 1;86(S422):103-5.

57. Pechtel P, Lyons-Ruth K, Anderson CM, et al. Sensitive periods of amygdala development: The role of maltreatment in preadolescence. Neurolmage. 2014 Aug $15 ; 97: 236-44$.

58. Benedetti F, Radaelli D, Poletti S, et al. Emotional reactivity in chronic schizophrenia: structural and functional brain correlates and the influence of adverse childhood experiences. Psychological Medicine. 2011 Mar 1;41(3):509-19.

59. English Longitudinal Study of Ageing. About ELSA. https://www.elsaproject.ac.uk/about-elsa. Updated Dec 17, 2019. Accessed Jul 8, 2020. 
Table 1. Sample characteristics by ACE exposure status, English Longitudinal Study of Ageing, 2006/07 $-2016 / 17$

\begin{tabular}{|c|c|c|c|c|c|c|}
\hline \multirow[t]{2}{*}{ Characteristic } & \multicolumn{2}{|c|}{$\begin{array}{l}\text { Overall } \\
(5,223)\end{array}$} & \multicolumn{2}{|c|}{$\begin{array}{l}\text { No ACEs } \\
(3,238)\end{array}$} & \multicolumn{2}{|c|}{$\begin{array}{l}\text { Any ACEs } \\
(1,985)\end{array}$} \\
\hline & $\mathbf{N}$ & $\%$ & $\mathbf{N}$ & $\%$ & $\mathbf{N}$ & $\%$ \\
\hline Female & 2,906 & 55.6 & 1,772 & 54.7 & 1,134 & 57.1 \\
\hline Baseline age $^{a}$ & \multicolumn{2}{|c|}{$67.7(9.0)$} & \multicolumn{2}{|c|}{$67.9(9.1)$} & \multicolumn{2}{|c|}{$67.4(8.7)$} \\
\hline Non-White & 74 & 1.4 & 39 & 1.2 & 35 & 1.8 \\
\hline Married or living as married & 3,621 & 69.3 & 2,262 & 69.9 & 1,359 & 68.5 \\
\hline Experienced financial hardship during & 138 & 2.6 & 50 & 1.5 & & 4.4 \\
\hline Number of childhood household amenities ${ }^{a}$ & \multicolumn{2}{|c|}{$2.7(1.5)$} & \multicolumn{2}{|c|}{$2.8(1.5)$} & & 1.6) \\
\hline \multicolumn{7}{|l|}{ Highest educational qualification } \\
\hline No qualification & 1,556 & 29.8 & 929 & 28.7 & 627 & 31.6 \\
\hline $\begin{array}{l}\text { Secondary education (e.g. graduate certificate of secondary } \\
\text { education or equivalent) }\end{array}$ & 2,506 & 48.0 & 1,570 & 48.5 & 936 & 47.2 \\
\hline Post-secondary education (e.g. university or higher) & 1,161 & 22.2 & & 22.8 & 422 & 21.3 \\
\hline \multicolumn{7}{|l|}{ Father's occupation at age 14} \\
\hline Skill level 1 (casual jobs/armed fc & 196 & 3.8 & 105 & 3.2 & 91 & 4.6 \\
\hline Skill level 2 (administrative/cleri & 2,453 & 47.0 & 1551 & 47.9 & 902 & 45.4 \\
\hline Skill level 3 (professional/technical) & 638 & 12.2 & 414 & 12.8 & 224 & 11.3 \\
\hline Skill level 4 (manager/owner) & 639 & 12.2 & 450 & 13.9 & 189 & 9.5 \\
\hline Other job & 1,142 & 21.9 & 660 & 20.4 & 482 & 24.3 \\
\hline Retired or unemployed & & 3.0 & 58 & 1.8 & 97 & 4.9 \\
\hline \multicolumn{7}{|l|}{ Number of books in household at age 10} \\
\hline $0-10$ books & & 26.7 & 767 & 23.7 & 627 & 31.6 \\
\hline $11-25$ books & & 24.0 & 807 & 24.9 & 448 & 22.6 \\
\hline $26-100$ books & 1,494 & 28.6 & 997 & 30.8 & 497 & 25.0 \\
\hline $101-200$ books & 450 & 8.6 & 294 & 9.1 & 156 & 7.9 \\
\hline More than 200 books & 381 & 7.3 & 254 & 7.8 & 127 & 6.4 \\
\hline Don't know/not applicable & 249 & 4.8 & 119 & 3.7 & 130 & 6.5 \\
\hline \multicolumn{7}{|l|}{ Health characteristics } \\
\hline Cancer & 471 & 9.0 & 288 & 8.9 & 183 & 9.3 \\
\hline Diabetes & 511 & 9.8 & 318 & 9.8 & 193 & 9.7 \\
\hline Lung disease & 376 & 7.2 & 192 & 5.9 & 184 & 9.3 \\
\hline Heart disease & 1,694 & 32.4 & 1,030 & 31.8 & 664 & 33.5 \\
\hline Depression & 256 & 4.9 & 125 & 3.9 & 131 & 6.6 \\
\hline Number of mobility impairments & \multicolumn{2}{|c|}{$2(2.5)^{\mathrm{a}}$} & \multicolumn{2}{|c|}{$1.8(2.4)^{\mathrm{a}}$} & \multicolumn{2}{|c|}{$2.1(2.6)^{a}$} \\
\hline
\end{tabular}

ACE $=$ adverse childhood experience

a Values are expressed as mean (standard deviation).

${ }^{b}$ The possible value range for number of childhood household amenities was 0-5. 
Table 2. Results from linear mixed-effects models for the associations between ACEs and memory function and decline, English Longitudinal Study of Ageing, 2006/07-2016/17 ( $N=5,223)$

\begin{tabular}{|c|c|c|c|c|c|}
\hline \multirow[t]{2}{*}{ ACEs } & \multicolumn{2}{|c|}{$\begin{array}{c}\text { Model Set } 1^{\text {a }} \\
\text { (without childhood SES) }\end{array}$} & \multicolumn{3}{|c|}{$\begin{array}{l}\text { Model Set } 2^{\mathrm{b}} \\
\text { (with childhood SES) }\end{array}$} \\
\hline & $\beta$ & $95 \% \mathrm{Cl}$ & $\beta$ & $95 \% \mathrm{Cl}$ & \\
\hline \multicolumn{6}{|l|}{ Physically abused by parents } \\
\hline Intercept (baseline memory without ACE) ${ }^{c}$ & 2.136 & $0.884,3.388$ & 0.918 & $0.312,2.149$ & $\overrightarrow{\overrightarrow{0}}$ \\
\hline $\begin{array}{l}\text { Mean difference for those who were physically abused } b \\
\text { parents }\end{array}$ & -0.064 & $-0.203,0.075$ & -0.076 & $14,0.061$ & \\
\hline Time $^{d}$ & -0.069 & $-0.075,-0.063$ & -0.070 & $-0.076,-0.063$ & \\
\hline Time $x$ physically abused by parents ${ }^{d}$ & -0.011 & $-0.052,0.029$ & -0.011 & $-0.051,0.029$ & \\
\hline \multicolumn{6}{|l|}{ Serious physical attack/assault } \\
\hline Intercept (baseline memory without ACE) ${ }^{\mathrm{c}}$ & 2.165 & $0.911,3.419$ & 0.947 & $-0.284,2.178$ & $\stackrel{\circ}{\frac{0}{0}}$ \\
\hline $\begin{array}{l}\text { Mean difference for those who experienced physical } \\
\text { attack/assault }\end{array}$ & -0.204 & $-0.443,0.035$ & -0.217 & $-0.454,0.020$ & $\overbrace{3}^{\circ}$ \\
\hline Time $^{d}$ & -0.070 & $-0.076,-0.064$ & -0.071 & $-0.077,-0.064$ & \\
\hline Time $x$ serious physical attack/assault ${ }^{d}$ & 0.056 & $-0.007,0.118$ & 0.056 & $-0.006,0.119$ & \\
\hline \multicolumn{6}{|l|}{ Sexual assault } \\
\hline Intercept (baseline memory without ACE) ${ }^{\mathrm{C}}$ & & $0.842,3.346$ & 0.873 & $-0.356,2.102$ & 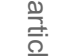 \\
\hline Mean difference for those sexually assaulted & & $-0.066,0.202$ & 0.064 & $-0.068,0.197$ & \\
\hline Time $^{d}$ & & $-0.076,-0.064$ & -0.070 & $-0.077,-0.064$ & $\frac{O}{O_{0}^{\circ}}$ \\
\hline Time $\times$ sexual assault ${ }^{d}$ & & $-0.015,0.055$ & 0.019 & $-0.016,0.054$ & $\overrightarrow{8}$ \\
\hline \multicolumn{6}{|l|}{ Parental drinking/drug use/mental health } \\
\hline Intercept (baseline memory without ACE) ${ }^{\mathrm{C}}$ & 2.148 & $0.896,3.401$ & 0.908 & $-0.324,2.140$ & \\
\hline $\begin{array}{l}\text { Mean difference for } \\
\text { drinking/drug use/m }\end{array}$ & -0.041 & $-0.143,0.062$ & 0.007 & $-0.093,0.108$ & \\
\hline Time $^{d^{d}}$ & -0.069 & $-0.075,-0.063$ & -0.070 & $-0.076,-0.063$ & בְ \\
\hline Time $\mathrm{x}$ parental drinking/drug use/mental health ${ }^{d}$ & -0.006 & $-0.034,0.022$ & -0.006 & $-0.034,0.022$ & $\vec{N}$ \\
\hline \multicolumn{6}{|l|}{ Parents argue or fight very often } \\
\hline Intercept (baseline memory without ACE) ${ }^{\mathrm{C}}$ & 2.109 & $0.855,3.362$ & 0.857 & $-0.374,2.09$ & $\frac{k}{5}$ \\
\hline $\begin{array}{l}\text { Mean difference for those whose parents argued or } \\
\text { fought very often }\end{array}$ & -0.003 & $-0.062,0.056$ & 0.028 & $-0.030,0.085$ & \\
\hline Time $^{d}$ & -0.072 & $-0.079,-0.065$ & -0.072 & $-0.079,-0.066$ & 8 \\
\hline Time $x$ parents argue or fight very often ${ }^{d}$ & 0.012 & $-0.003,0.028$ & 0.012 & $-0.003,0.028$ & $\overline{\overline{\mathbb{O}}}$ \\
\hline \multicolumn{6}{|l|}{ Separated from mother for 6 months or more } \\
\hline Intercept (baseline memory without ACE) ${ }^{\mathrm{C}}$ & 2.066 & $0.808,3.324$ & 0.879 & $-0.357,2.115$ & : \\
\hline $\begin{array}{l}\text { Mean difference for those separated from mother for } 6 \\
\text { months or more }\end{array}$ & -0.010 & $-0.080,0.061$ & 0.011 & $-0.057,0.079$ & 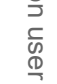 \\
\hline Time ${ }^{d}$ & -0.068 & $-0.074,-0.061$ & -0.068 & $-0.075,-0.062$ & ९ \\
\hline Time $x$ separated from mother for 6 months or more ${ }^{d}$ & -0.013 & $-0.030 \quad 0.005$ & -0.013 & $-0.030,0.005$ & $\vec{N}$ \\
\hline \multicolumn{6}{|l|}{ Maternal death } \\
\hline Intercept (baseline memory without ACE) ${ }^{c}$ & 2.126 & $0.874,3.378$ & 0.906 & $-0.325,2.136$ & $\sum_{\substack{n \\
n}}^{2}$ \\
\hline $\begin{array}{l}\text { Mean difference for those whose mother died before age } \\
16\end{array}$ & -0.137 & $-0.288,0.015$ & -0.068 & $-0.218,0.083$ & 莡 \\
\hline Time $^{d}$ & -0.069 & $-0.075,-0.063$ & -0.070 & $-0.076,-0.063$ & \\
\hline Time $x$ maternal death ${ }^{d}$ & -0.015 & $-0.058,0.028$ & -0.015 & $-0.057,0.028$ & \\
\hline
\end{tabular}




\section{Most of childhood in a single-mother family}

Intercept (baseline memory without ACE) ${ }^{c}$

Mean difference for those who spent most of childhood in a single mother family

Time $^{d}$

Time $x$ most of childhood in single-mother family ${ }^{d}$

\section{Been in residential care institution/fostered}

Intercept (baseline memory without ACE) ${ }^{\mathrm{C}}$

Mean difference for those who have been in residential care institution or were fostered

Time $^{d}$

Time $\mathrm{x}$ been in residential care institution/fostered ${ }^{d}$

\section{Any adverse childhood experience}

Intercept (baseline memory without any ACE) ${ }^{\mathrm{c}}$

Mean difference for those with any ACE

Time $^{d}$

$\begin{array}{llll}2.113 & 0.861,3.365 & 0.911 & -0.319,2.142 \\ -0.048 & -0.145,0.048 & 0.035 & -0.059,0.129 \\ -0.069 & -0.076,-0.063 & -0.070 & -0.076,-0.064 \\ -0.000 & -0.029,0.028 & 0.000 & -0.028,0.029 \\ & & & \\ 2.122 & 0.870,3.374 & 0.903 & -0.328,2.134 \\ -0.190 & -0.343,-0.036 & -0.124 & -0.273,0.025 \\ -0.069 & -0.076,-0.063 & -0.070 & -0.076,-0.064 \\ 0.003 & -0.036,0.042 & 0.003 & -0.036,0.042 \\ & & & \\ 2.123 & 0.872,3.374 & 0.902 & -0.329,2.133 \\ -0.021 & -0.068,0.027 & 0.021 & -0.025,0.068 \\ -0.069 & -0.077,-0.061 & -0.070 & -0.077,-0.062 \\ -0.001 & -0.013,0.012 & -0.001 & -0.013,0.012\end{array}$

Time $x$ any adverse childhood experience ${ }^{d}$

$\mathrm{ACE}=$ adverse childhood experience; $\mathrm{Cl}=$ confidence interval; $\mathrm{SES}=$ socioeconomic status

${ }^{a}$ Models adjust for baseline age, baseline age ${ }^{2}$, sex, ethnicity, time, and are weighted for non-response to the Life History interview.

${ }^{b}$ Models adjust for baseline age, baseline age ${ }^{2}$, sex, ethnicity, time, childhood financial hardship, number of childhood household amenities, number of books in home at age 10, and father's occupation at age 14, and are weighted for non-response to the Life History interview.

${ }^{\mathrm{C}}$ Intercepts represent mean baseline memory function for individuals in the reference categories of covariates, without the ACE.

${ }^{d}$ Coefficients are expressed as changes in standard deviation units of the baseline distribution of memory scores over 2-year intervals. 
Table 3. The association between total number of ACEs and memory function and decline, English Longitudinal Study of Ageing, 2006/07 to 2016/17

\begin{tabular}{lcc}
\multicolumn{1}{c}{ Cumulative ACEs } & $\boldsymbol{\beta}^{\mathbf{a}}$ & $\mathbf{9 5 \%} \mathbf{C l}$ \\
\hline \hline Intercept (baseline memory without any ACEs) & 0.906 & $-0.325,2.137$ \\
Total number of ACEs & 0 & \\
0 & 0.027 & $-0.025,0.079$ \\
1 & 0.024 & $-0.063,0.110$ \\
2 & -0.031 & $-0.157,0.096$ \\
$3+$ & 0.716 & \\
$P$-value for linear trend & & \\
\hline Total number of ACEs x Time & 0 & $-0.014,0.014$ \\
0 & -0.000 & $-0.028,0.019$ \\
1 & -0.005 & $-0.025,0.043$ \\
2 & 0.009 & \\
$3+$ & 0.935 & \\
$P$-value for slope & &
\end{tabular}

$\mathrm{ACE}=$ adverse childhood experience $; \mathrm{Cl}=$ confidence interval

${ }^{a}$ Models adjust for baseline age, baseline age ${ }^{2}$, sex, ethnicity, time, childhood financial hardship, number of childhood household amenities, number of books in home at age 10, and father's occupation at age 14, and are weighted for non-response to the Life History interview. Coefficients are expressed as changes in standard deviation units of the baseline distribution of memory scores over 2-year intervals.

${ }^{\mathrm{b}}$ The intercept represents mean baseline memory function for individuals in the reference categories of covariates, without any ACEs. 
Figure 1. Study flow diagram of the participants' selection into the study, English Longitudinal Study of Ageing, 2006/07 to 2016/17. Figure title: Study Flow Diagram

Figure 2. Predicted memory scores over the follow-up by ACE, English Longitudinal Study of Ageing, 2006/07 to 2016/17. Predicted memory scores are expressed at each time point in standard deviation units of the baseline distribution and are adjusted for baseline age, baseline age ${ }^{2}$, sex, ethnicity, time, childhood financial hardship, number of childhood household amenities, number of books in home at age 10, and father's occupation at age 14, and weighted for non-response to the Life History interview. A) Any ACE; B) Physical abuse by parents; C) Physical attack or assault; D) Sexual assault; E) Parental drinking/drug use/mental health; F) Parents argue/fíght often; G) Separated from mother; H) Maternal death; I) Single-mother family; J) Residential care institution/fostered. $\mathrm{ACE}=$ adverse childhood experience. Figure title: Individual ACEs

Figure 3. Predicted memory scores over the follow-up by total number of ACEs, English Longitudinal Study of Ageing 2006-2017. Predicted memory scores at each time point are expressed in standard deviation units of the baseline distribution and are adjusted for baseline age, baseline age ${ }^{2}$, sex, ethnicity, time, childhood financial hardship, number of childhood household amenities, number of books in home at age 10, and father's occupation at age 14, and weighted for non-response to the Life History interview. $\mathrm{ACE}=$ adverse childhood experience. Figure title: Total ACEs 
Wave 3 Core Members who Completed the Life History Interview and Self-Completion Questionnaire $(n=5,260)$

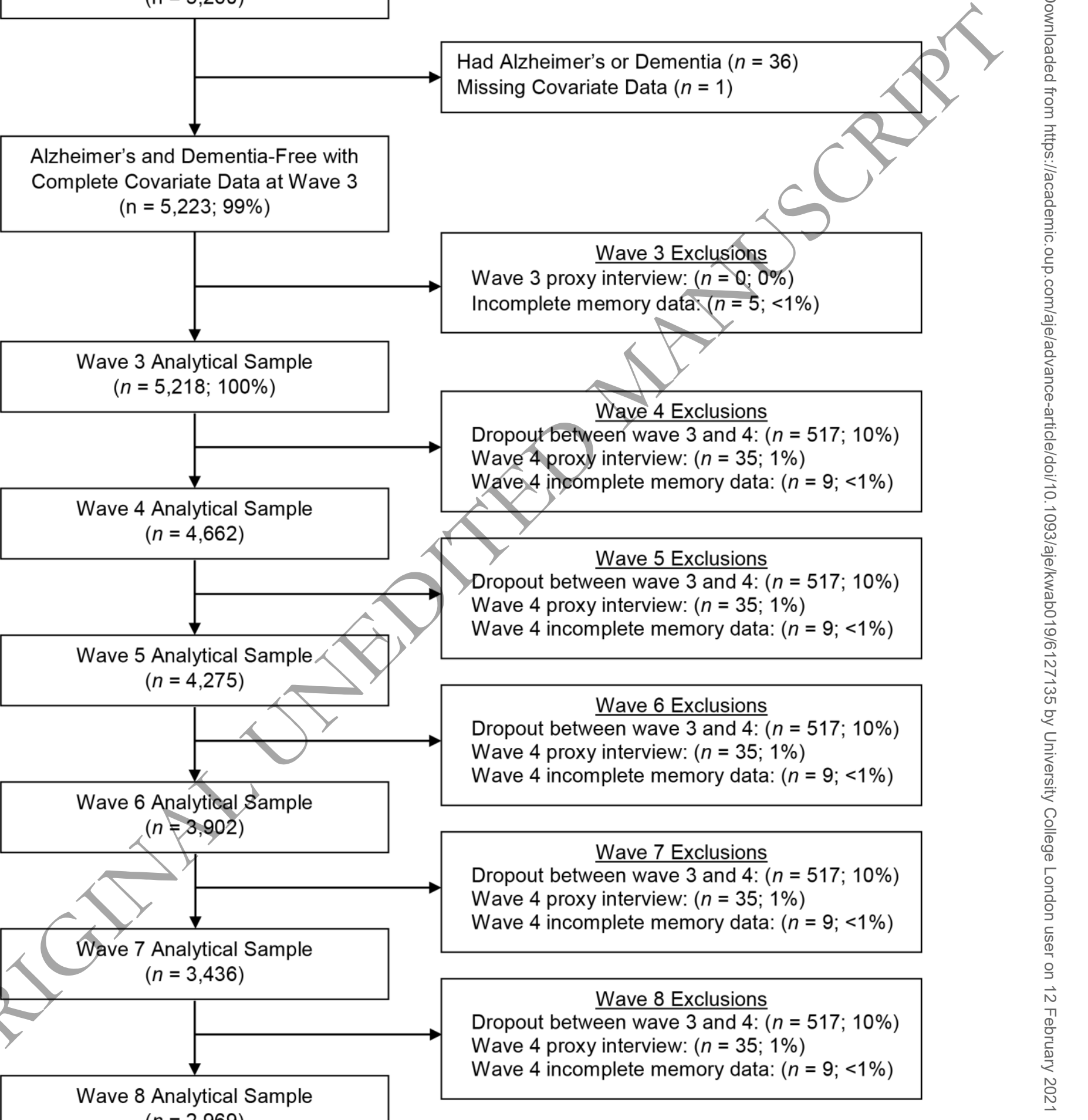


A)

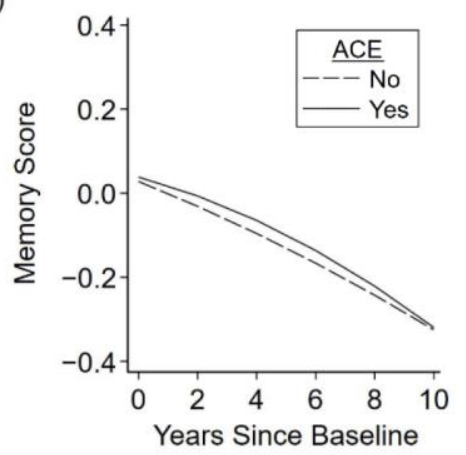

D)

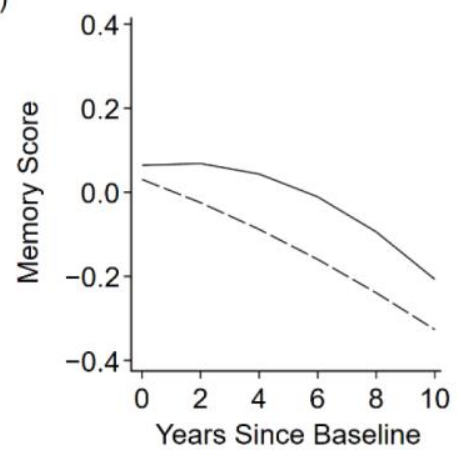

G)

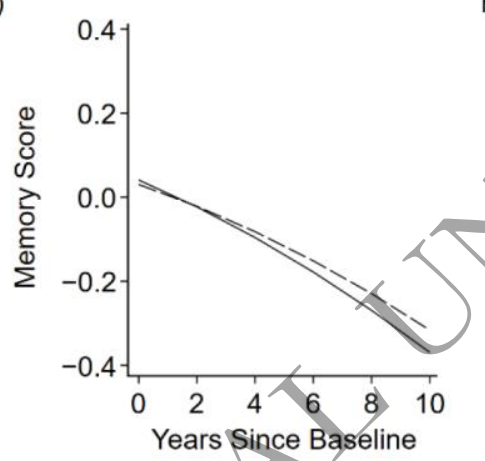

J)

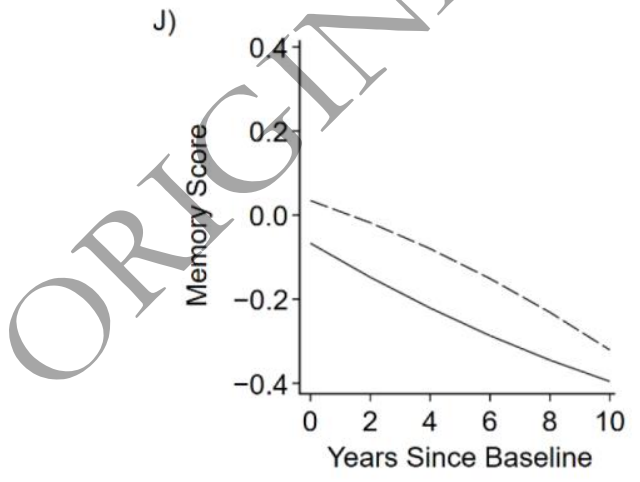

B)

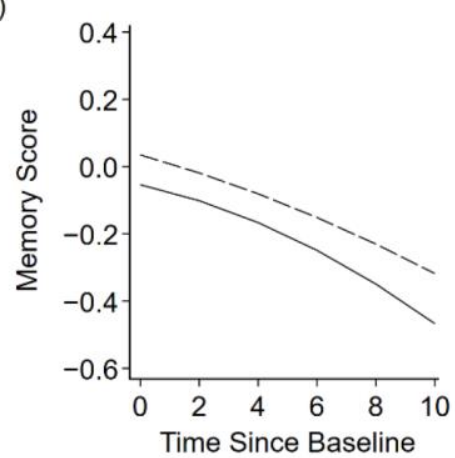

E)

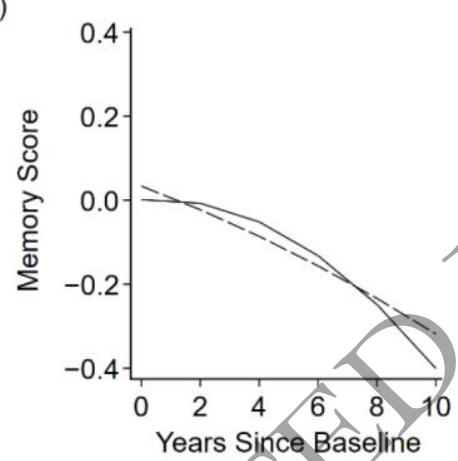

H)

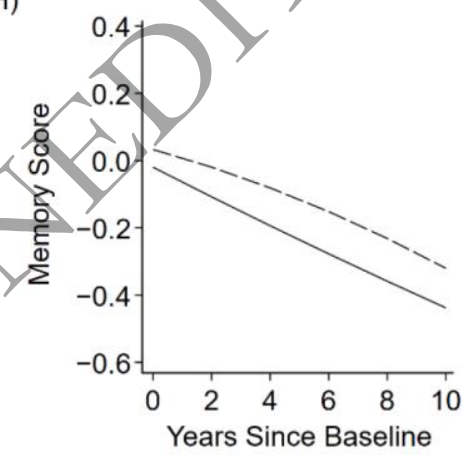

C)

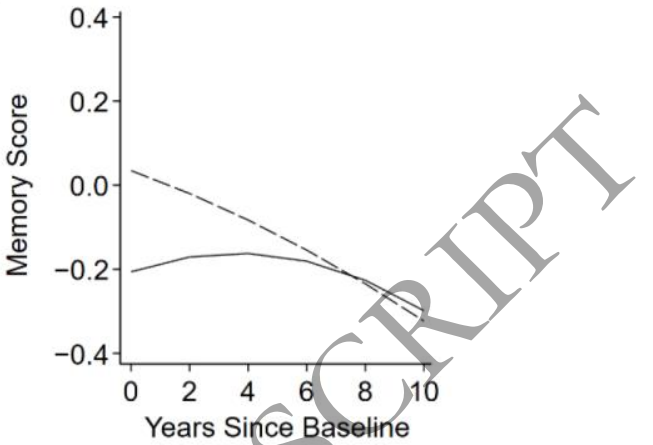

F)

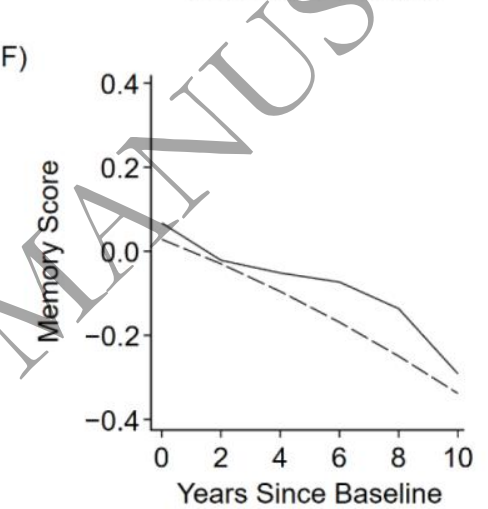

I)

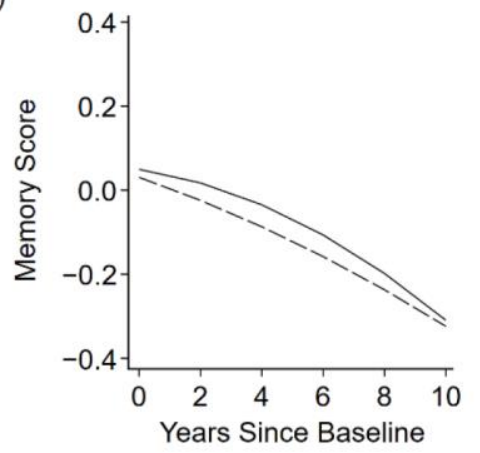




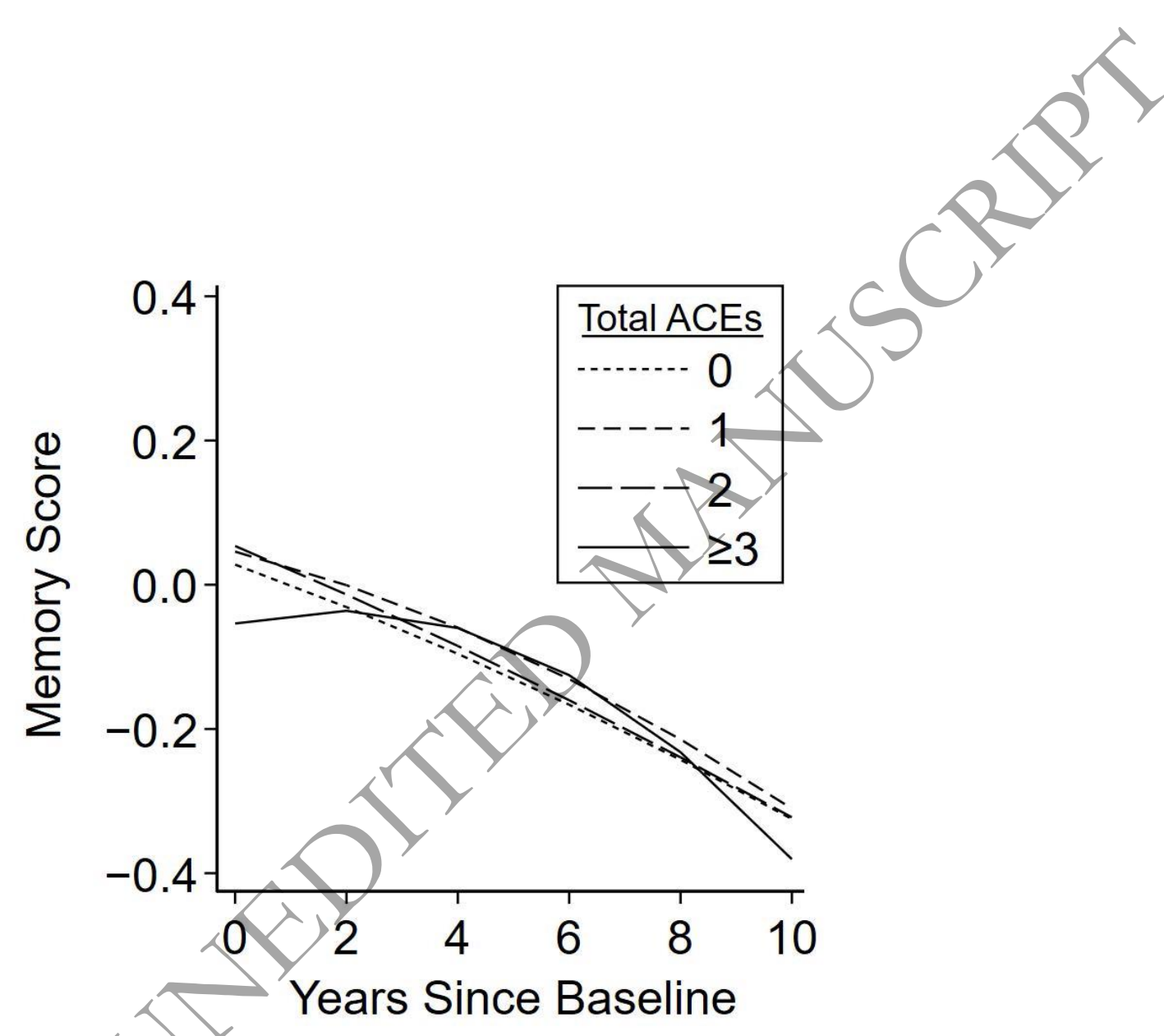

